\title{
Data Warehouse Perusahaan Bidang Geomatika dan Manajemen Informasi
}

\author{
Ambar Tri Hapsari ${ }^{1}$ \\ ${ }^{1}$ Teknik Informatika, Universitas Indraprasta PGRI, Jakarta, Indonesia \\ e-mail: ${ }^{1}$ ambar.trihapsari@gmail.com
}

Submitted Date: February $23^{\text {rd }}, 2021$

Revised Date: June $04^{\text {th }}, 2021$
Reviewed Date: June $02^{\text {nd }}, 2021$

Accepted Date: June $15^{\text {th }}, 2021$

\begin{abstract}
PT. Duta Astakona Girinda is a company in the field of geomatics and spatial information management. This company was founded in early 1987 to provide consulting services for spatial information management applications, hardware, software, implementation and communication. As the experience of PT. Duta Astakona Girinda as an information and communication technology management application consulting service provider, continues to innovate. Providing services such as mapping planning, thematic maps of various needs, cartography, digitizing services, scanning, plotting. This company also provides GIS market application development services, GIS and MIS integration. Other services include conducting training, seminars and creating a spatial database. The company needs a warehouse information system to make it easier for warehouse administrators to manage incoming and outgoing goods at PT Duta Astakona Girinda. The role of this Information System is also inseparable from the users of equipment that are able to overcome the inability of human labor. The desktop application created here is internal in nature, which can only be accessed by employees.
\end{abstract}

Keywords: Bank; Housing; Credit; Software; Java

\section{Abstrak}

PT. Duta Astakona Girinda adalah perusahaan dalam bidang geomatika dan manajemen informasi spasial. Perusahaan ini berdiri pada awal tahun 1987 melayani konsultasi software aplikasi manajemen informasi spasial, hardware, software, implementasi dan komunikasi. Seiring bertambahnya pengalaman PT. Duta Astakona Girinda sebagai perusahaan penyedia jasa konsultasi aplikasi manajemen teknologi informasi dan komunikasi, terus menerus melakukan inovasi. Menyediaan pelayanan seperti perencanaan pemetaan, peta tematik macam-macam kebutuhan, kartografi, pelayanan digitasi, scanning, pengeplotan. Perushaan ini juga menyediakan pelayanan pengembangan aplikasi GIS market, integrasi GIS dan MIS. Pelayanan lain adalah mengadakan pelatihan, seminar dan pembuatan database spasial. Perusahaan membutuhkan sebuah sistem informasi Warehouse di mana untuk memudahkan administrator Warehouse untuk manajemen barang masuk dan keluar pada PT Duta Astakona Girinda. Peranan Sistem Informasi ini juga tidak terlepas dari pengguna peralatan yang mampu mengatasi ketidakmampuan dari tenaga manusia. Aplikasi desktop yang dibuat di sini sifatnya internal, yang hanya bisa diakses oleh karyawan.

Kata kunci: Geomatika; Warehouse; Java; MIS; GIS

\section{Pendahuluan}

Sebuah kegiatan bisnis seperti perusahaan adalah wadah komersial yang berperan dalam perekonomian nasional menjadi lebih maju. Kegiatan bisnis ini dapat membuka lapangan kerja lebih luas untuk masyarakat mmaka keberadaannya sangan penting dapat meningkatkan kesejahteraan masyakat.

Kegiatan bisnis dapat bergerak dengan memilih khusus dalam satu bidang tertentu saja. Contoh kegiatan bisnis ini adalah perusahaan dagang, perusahaan pelayanan dan masih banyak yang lain. Suatu kegiatan bisnis produk-produk 
mereka membutuhkan tempat penyimpanan. Produk suatu perusahaan dengan jumlah yang begitu banyak dapat dibuatkan data-data untuk lebih mudah dalam pengelolaannya.

Teknologi yang sedang berkembang saat ini dapat membantu perusahaan untuk terus berkembang agar mampu bersaing dengan perusahaan lainnya. Membutuhan sumber daya manusia dengan keahlian mumpuni dalam bidang teknologi Komputer. Teknologi computer sudah banyak menunjang pekerjaan pegawai dalam suatu kegiatan bisnins. Bantuan teknologi bagi perusahaan diterapkan dibanyak bagian. Penerapan tersebut contohnya pengelolaan data seperti pengelolaan data pergudangan membantu bagian gudang mengolah data produk yang masuk dan keluar.

Manfaat teknologi komputer membantu pekerjaan dalam mengola data menjadi lebih cepat. Pengambilan suatu keputusan menjadi lebih akurat, hemat tempat yang cukup banyak. Teknologi ini di butuhkan dalam kegiatan bisnis baik bidang ekonomi atau pelayanan seperti halnya pada PT.Duta Astakona Girinda.

\section{Metode Penelitian}

Warehouse bermakna tempat utuk menyimpan produk supaya tidak rusak, aman dan tetap tersedia jika sewaktu-waktu digunakan sehingga kegiatan produksi menjadi lancar. Ditempat tersebut terjadi kegiatan proses penyimpanan tata letak serta perawatan barang yang menjadi asset.

Masalah yang terjadi pada sistem informasi Warehouse PT.Duta Astakona Girinda adalah sebagai berikut:

1. Pengelolaan data belum standar karena belum menggunakan database.

2. Pembuatan laporan belum sempurna secara baik karena masih harus diolah sebelum dicetak.

3. Proses pencarian data sangat lama karena dilakukan memilih satu persatu dokumen. Dokumen tersebut disimpan di tempat yang tidak tersusun dengan baik dan tidak ada pengkodean sehingga pencarian menjadi lebih saulit.

4. Bagian gudang tidak memiliki perangkat yang baik mendukung kegiaatan persediaan barang.

Solusi dari permasalahan dalam penelitian ini meliputi sistem informasi laporan barang masuk dan keluar di Warehouse PT Duta Astakona Girinda.

Proses perancangan sistem informasi warehouse PT Duta Astakona Girinda. Dibuat untuk pencatatan, penelusuran, mutasi dan laporan data produk untuk dilaporakan kepada pimpinan. Secara keseluruhan tahapan dari proses perancangan sistem ini dibuat secara sistematis, terstruktur dan terarah. Sistem ini diharapkan mendukung kinerja yang lebih efesien dan kecepatan operasional instansi PT Duta Astakona Girinda. Sistem ini dapat menjadi sumber informasi yang baik yang di butuhkan pada warehouse di PT Duta Astakona Girinda.

\section{Perancangan Sistem Informasi}

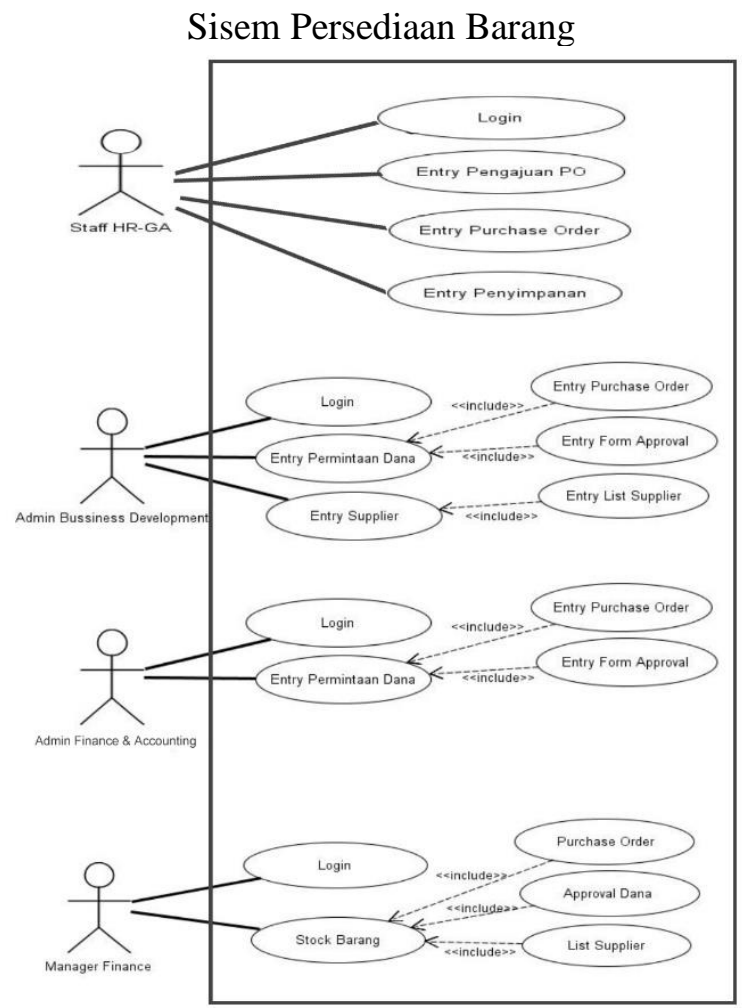

Gambar 1 Diagram Use Case Sistem Persediaan

Pada Gambar 1 berisi Diagram Use Case, dimana diagram ini menggambarkan pengguna dari sistem informasi yang di bangun dalam penelitian ini. Penggambaran pengguna sistem dilambangkan dengan aktor. Aktor pada diagram digambarkan berinteraksi dengan sistem dari posisi luar sistem. 


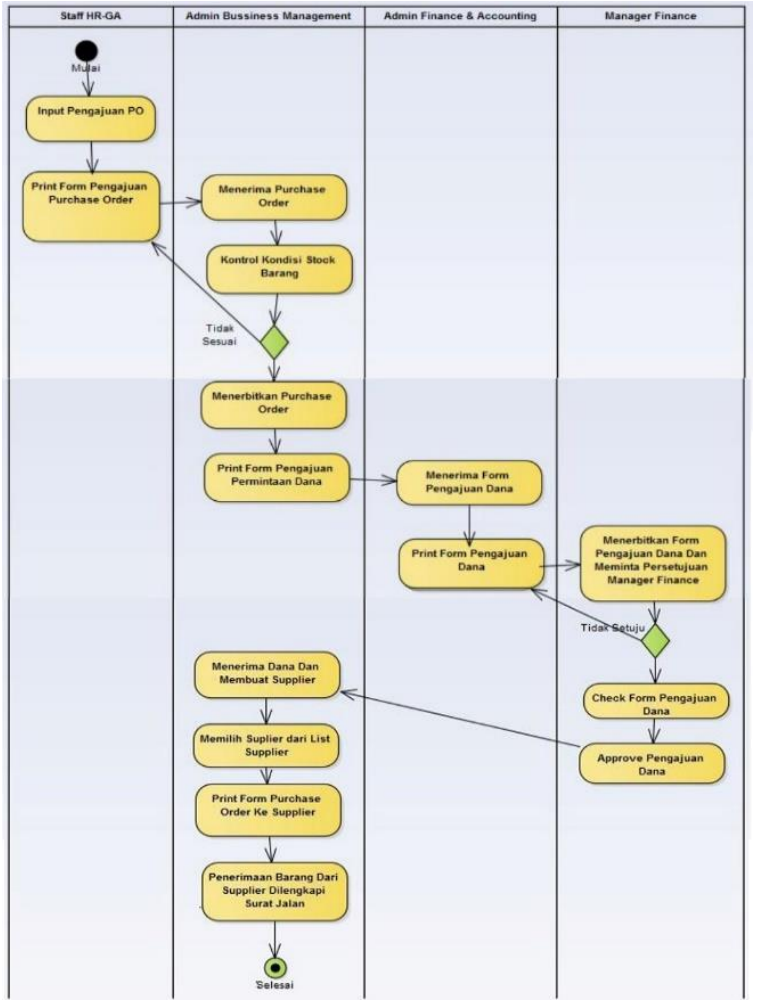

Gambar 2 Diagram Activity Sistem Persediaan

Gambar 2 adalah gambar diagram activity yang menggambarkan proses alur dari bisnis proses sistem pada penelitian ini. Pada gambar berisi bagian manager, bagian keuangan, bagian gudang dan staff sebagai admin sistem.

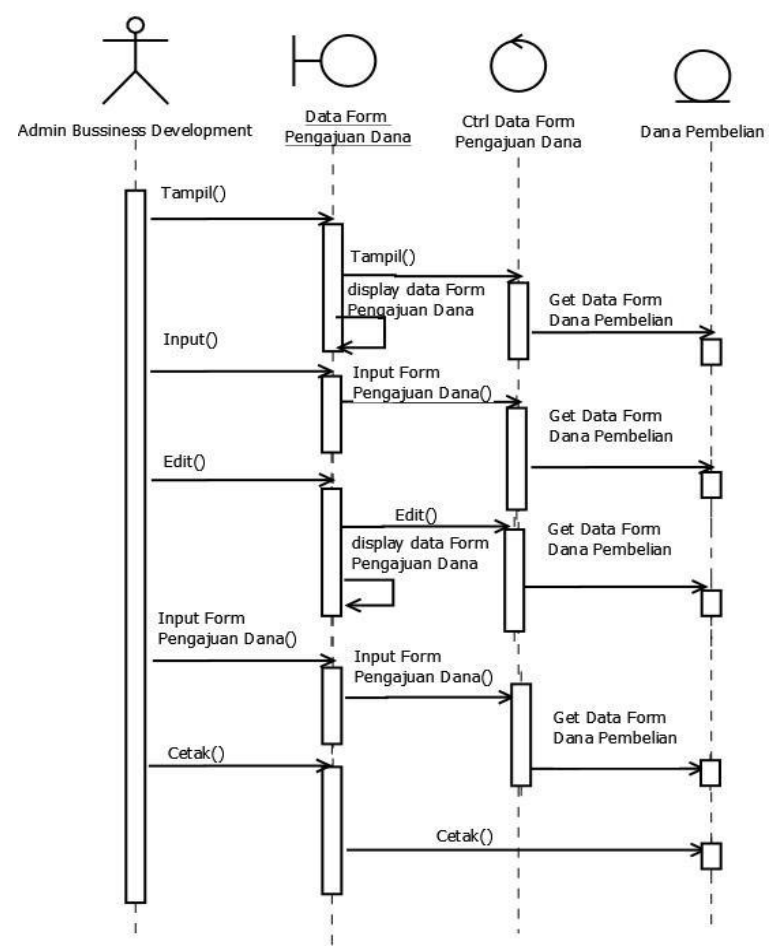

Gambar 3. Diagram Sequence Persediaan
Pada gambar 3 berisi diagram sequence dari proses pemesanan barang kepada supplier. Proses pemesanan ini menunggu persetujuan dari bagian keuangan.

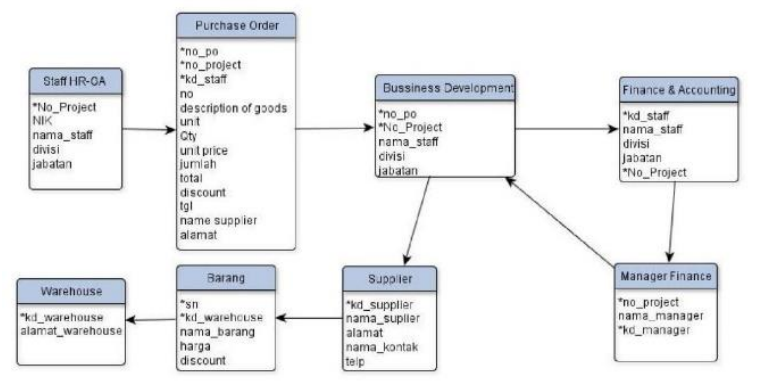

Gambar 4. Diagram Class Sistem Pemesanan

Gamnar 4 adalah gambar diagram class dari sistem. Diagram class ini berisi objek atau elemen daris sistem yang disimpan dalam database. Dari diagram class terbentuk tabeltabel sesuai dengan data dan fungsi masingmasing.

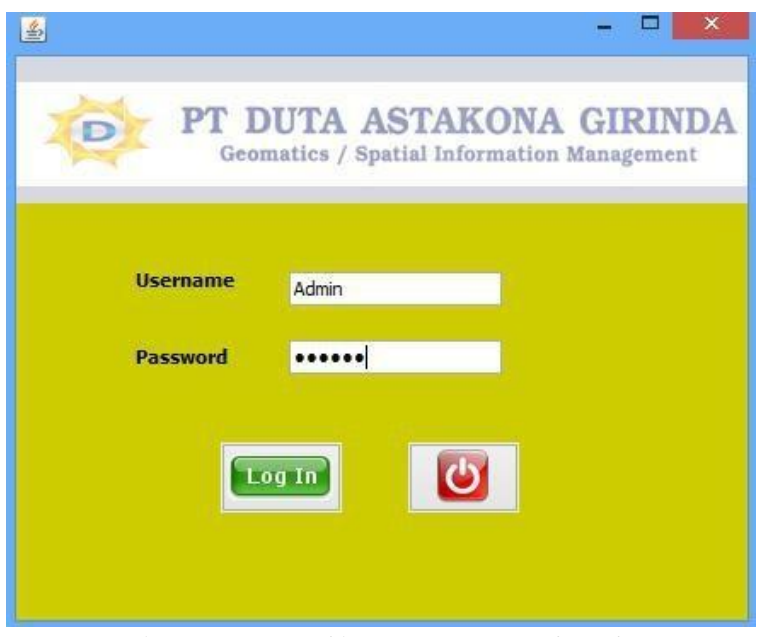

Gambar 5. Tampilan Menu Login Sistem

Pada Gambar 5 berisi tampilan dari halaman sistem login. Pengguna sistem ini dapat mengakses halaman-halaman yang ada di sistem namun harus memiliki hak akses berupa user password.

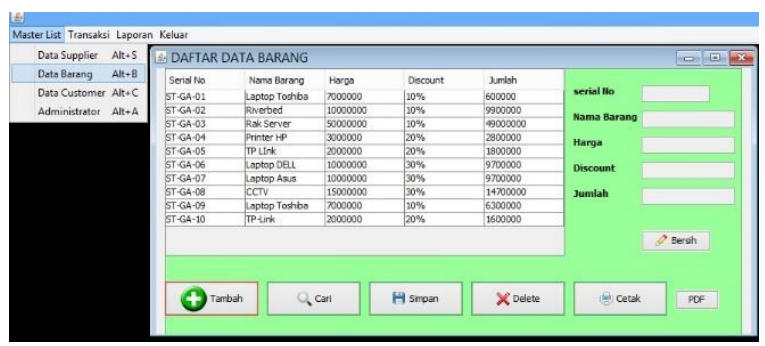


Gambar 6 Tampilan Menu Barang

Pada gambar 6 merupakan tampilan halaman menu pengolahan data barang. Pada menu pengolahan data barang datap melakukan pengolahan seperti input data barang, edit data barang dan hapus data barang.

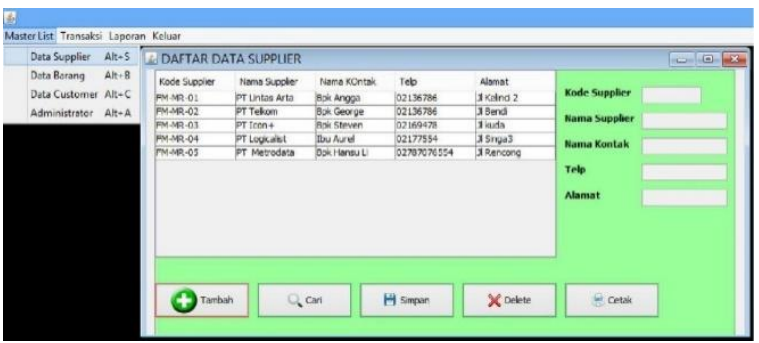

Gambar 7 Tampilan Menu Suplaier

Pada gambar 7 merupakan tampilan halaman menu pengolahan data suplaier. Pada menu pengolahan data barang datap melakukan pengolahan seperti input data, edit data dan hapus data suplier.

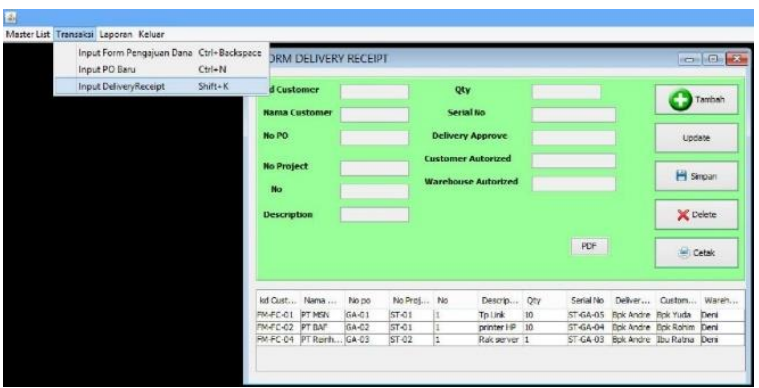

Gambar 8. Tampilan Menu Transaksi

Pada gambar 8 merupakan tampilan halaman menu transaksi pesediaan. Pada menu pengolahan data barang datap melakukan pengolahan seperti input data pembelian, edit data pemesanan dan hapus data pembelian dan pemesanan.

\section{Kesimpulan}

Penelitian tentang datawarehouse ini selesai dilakukan dan menghasilkan kesimpulan yang dapat diambil sebagai berikut:

a. Sistem informasi warehouse yang berbasis desktop ini dapat membantu mempermudah pengolahan data dan penyimpanan barang karena penggunaannya yang sistematis, terstruktur dan terarah, sehingga mampu membantu kinerja perusahaan di PT Duta Astakona Girinda menjadi lebih cepat, efisien dan efektif. b. Informasi yang disediakan oleh sistem informasi warehouse berbasis desktop ini terdiri dari informasi jumlah stok barang pakai dan untuk produksi. Informasiinformasi yang tersedia pada aplikasi sistem informasi warehouse ini dapat mempermudah pekerja dalam menemukan informasi data yang dibutuhkan

\section{Saran}

Berikut ini merupakan saran yang diberikan untuk menyempurkan penelitian selanjutnya.

a. Sistem informasi warehouse disini belum menggunakan database dan masih menggunakan Ms Excel. Sebaiknya sistem informasi warehouse ini lebih dikembangkan menjadi client-server sehingga pengolahan datanya menjadi lebih efektif dan efisien dari sistem yang telah dibuat.

b. Data warehouse bagian barang produksi harusnya terpisah dan dibuatkan sistem informasi seperti sistem yang sudah diterapkan di warehouse bagian stock jadi agar dapat membantu kinerja perusahaan PT. Duta Astakona Girinda.

\section{Referensi}

Chusman, P. K. (2007). Dasar-Dasar Database . Jakarta: Erlangga.

Hariyanto, B. (2010). Esensi-Esensi Bahasa Pemrogramann Java. Bandung: Informatika.

Henderi. (2006). Unified Modelling Languange. Tangerang: Raharja Enrichment Centre.

Indrajani. (2011). Perancangan Basis Data dalam All in One. Jakarta: Elex Media.

Ladjamudin, A. B. (2010). Analisa Dan Perancangan Sistem. Yohyakarta: Graha Ilmu.

McLeod, R. d. (2007). Sistem Informasi Manajemen. Jakarta: Salemba Empat.

Mulyanto, A. (2009). Sistem Informasi Konsep Dan Aplikasi. Yogyakarta: Pustaka Pelajar.

Mustakini, J. H. (2009). Analisis Dan Desain Sistem Informasi. Yogyakarta: Andi.

Mustakini, J. H. (2009). Perancangan Sistem Informasi Pengenalan . Yogyakarta: Pustaka Pelajar.

Mustakini, J. H. (2009). Sistem Informasi Teknologi. Yogyakarta: Andi Offset.

Nugroho, A. (2010). Rekayasa Perangkat Lunak Menggunakan UML dan Java. Yogyakarta: Andi Offset.

Pudjo, W. P. (2011). Menggunakan UML. Bandung: Informatika. 
Sutabri, T. (2012). Konsep Dasar Informasi. Yogyakarta: Andi Offset.

Sutanta, E. (2011). Basis Data Dalam Tinjauan Konseptual. Yogyakarta: Andi Offset.

Tata, S. (2016). Sistem Informasi Manajemen. Yogjakarta: Andi Offset. 